\title{
How Corporates in South Africa Are Using Serious Games in Business
}

\author{
Shiraz Amod and Sumarie Roodt ${ }^{(\varpi)}$ \\ University of Cape Town, Rondebosch, Cape Town 7700, South Africa \\ sumarie.roodt@uct.ac.za
}

\begin{abstract}
It has been shown that serious games are useful in the military, healthcare, and education sectors. Meanwhile corporate interest in serious gaming in business has rapidly grown internationally. However the level of awareness and adoption of serious gaming among South African corporates in business is still unclear.

This interpretive study explores South African corporate awareness of serious gaming in business and the barriers to its adoption. Semi-structured interviews were used to collect qualitative data from managers in Johannesburg Stock Exchange-listed companies. Eight participants were interviewed across four different industries. Data analysis was guided by the general inductive approach.

The absence of serious gaming adopters among the participants, and the general lack of awareness of serious gaming in business were identified as the most salient features. The analysis suggests that corporates currently use technologies related to serious games (e-learning, collaborative tools, and simulation tools), and that there is a demand for the greater promotion and use of serious gaming.

While the findings provide new insights into the level of serious gaming awareness, caution should be exercised when attempting to generalize these findings due to the small sample and the scarcity of prior research.
\end{abstract}

Keywords: Serious games $\cdot$ Serious gaming $\cdot$ Corporate $\cdot$ Barriers to adoption $\cdot$ Awareness $\cdot$ Digital Game-Based Learning $\cdot$ Commercial off the shelf $\cdot$ Serious games in business

\section{Introduction}

The contribution offers a novel understanding on the adoption and potential use of serious games in corporate business environments. Serious games use the artistic medium of games to deliver a message, teach a lesson, or provide an experience. A serious game is an "interactive computer application, with or without significant hardware component that has a challenging goal, is fun to play and engaging, incorporates some scoring mechanism, and supplies the user with skills, knowledge or attitudes useful in reality" (Bergeron 2006). Studies abound that show the application of serious games in the entertainment, military, healthcare, and education sectors (Levin 2010; Smith 2007; Zyda 2005). However, there are limited studies on the application within the corporate sector. The field of serious games is relatively new and 
therefore, limited research has been conducted in this area (Azadegan et al. 2012; Levin 2010). Few studies exist about the application of serious games in the South African business context. Therefore, the study serves to raise corporate awareness of serious games and the potential applications in the context of South Africa business.

\section{Literature Review}

\subsection{Definitions}

Serious games involve a broader spectrum of uses than Digital Game-Based Learning (Breuer and Bente 2010; Connolly et al. 2012; Michael and Chen 2006). DGBL is a term used in the domain of education as it involves the use of digital games primarily for learning purposes (Breuer and Bente 2010; Susi et al. 2007). Serious gaming relates to the concepts of virtual worlds and DGBL (Connolly et al. 2012; Susi et al. 2007). DGBL found in education involves applying digital games primarily for learning purposes (Breuer and Bente 2010; Susi et al. 2007). Virtual worlds are "computersimulated, usually 3-D, representations that allow avatars to interconnect and communicate in relatively lifelike environments" (Ives and Junglas 2008). These environments persist; continue to exist and undergo changes even when players are not present (Cox 2000; Ives and Junglas 2008). Serious games have their own virtual world in which players play the game (Breuer and Bente 2010; Levin 2010). Serious games can be divided into two broad categories: commercial off the shelf (COTS) games, and games developed specifically for educational or corporate purposes (Azadegan and Riedel 2012; Graafland et al. 2012). COTS involves re-purposing an existing game to harness the power of serious games without the risk and expense of developing a bespoke serious game that may not be sufficiently engaging (Connolly et al. 2012). Both categories of serious games are included in this study.

\subsection{Application of Serious Games}

Three broad application areas of serious games in business exist: (1) conducting training in a simulated environment; (2) as a platform for collaboration; and (3) as a tool for demonstrations and education (Fernandes et al. 2012; Herrlich 2007; Ives and Junglas 2008; Levin 2010; Michael and Chen 2006).

Training conducted with serious games, especially in simulated environments is prevalent (Michael and Chen 2006; Susi et al. 2007). Games offer a simulated environment in which training exercises can be performed, much like real-life training simulations (Graafland et al. 2012; Susi et al. 2007). There are benefits of using serious games over traditional forms of training. Serious games present a safe environment for performing training (Graafland et al. 2012; Oliveira et al. 2012). The simulation of a real life activity allows skills to be fine-tuned through practice in a risk-free environment without consequence (Graafland et al. 2012; Oliveira et al. 2012). Serious games can also be deployed as a collaborative platform among multiple people (Bozanta et al. 2012; Fernandes et al. 2012; Oliveira et al. 2012). Using the internet as a communication medium enables serious games to provide Multi-User Virtual Environments 
(MUVEs) in the form of virtual worlds (Bozanta et al. 2012). The MUVEs provide a virtual environment that players can communicate and collaborate to jointly achieve their goals (Fernandes et al. 2012). Collaboration enables people in different locations to collaborate effectively without needing to travel or for expensive teleconferencing technologies to be purchased (Bozanta et al. 2012; Fernandes et al. 2012; Levin 2010). Serious games are also employed for demonstrations and education (Herrlich 2007; Levin 2010). Serious games provide unique immersive environments that teach complex material (Susi et al. 2007). Serious games aid marketing and performing demonstrations of products or services (Herrlich 2007; Levin 2010). COTS games have been suitable for this purpose because of their low cost, fast implementation, and high level of engagement ("flow") (Herrlich 2007; Rankin and Shute 2010).

\subsection{Barriers to Adoption of Serious Games}

The application of serious games is new, especially in a business context (Azadegan et al. 2012). Companies which are unaware of serious games will not adopt them, and those which are aware of the concept, but not of the benefits are equally unlikely to adopt serious games (Azadegan et al. 2012). Perceptions of employees and managers towards games heavily influence the likelihood of adoption (Azadegan et al. 2012; Ives and Junglas 2008). Games perceived as easy and not contributing to training or promoting the company's purpose, will not be adopted (Azadegan et al. 2012; Ives and Junglas 2008). Based on the work by Azadegan et al. (2012) in the area of serious game adoption in businesses, four categories of barriers are identified: barriers with familiarity about serious games (familiarity barriers), financial barriers, barriers in terms of the practicality of serious games (practicality barriers), and the level of Information Technology facilities and support (IT facilities and support barriers) (Azadegan et al. 2012).

\section{Materials and Methods}

The primary research question asks, "What is the state of use of serious games by South African corporations in a business context?" Secondary questions asked include: (1) What is the level of awareness of serious games within South African corporates? (2) What uses for serious games are South African corporates embracing? (3) What barriers are preventing the adoption of serious games by South African corporates?

In-depth semi-structured interviews were conducted with corporate managers, who were prepared with a briefing on serious games before answering related questions on awareness and adoption. The work follows the study on the adoption of serious games in corporate training in the United Kingdom (Azadegan et al. 2012). The sample consists of eight South African corporations across a range of four industries that includes; Financial Services, Retail, Insurance, and Construction. A qualitative analysis of the interview transcripts was conducted via a thematic analysis. Thematic analysis was performed using open coding and then axial coding to assess the most common uses and barriers to adoption of serious games in South African corporations. To avoid 
biased results comparative analysis was only performed on the questions that were consistently posed to all subjects.

\section{Results and Data Analysis}

Interviews were conducted with eight participants from different South African corporations for this study. For a description of the sample data, the characteristics of the participants are summarized (See Table 1).

Table 1. Overview of participants

\begin{tabular}{l|l|l}
\hline Name & Organizational Role & Industry \\
\hline Participant A & Training Manager & Financial Services \\
\hline Participant B & Executive Manager: Learning and Development & Retail \\
\hline Participant C & Skills Development Manager & Construction \\
\hline Participant D & Learning and Growth Partner & Retail \\
\hline Participant E & Human Resources Programs Manager & Insurance \\
\hline Participant F & Training and Methodology Manager & Financial Services \\
\hline Participant G & Executive Head of Training & Insurance \\
\hline Participant H & General Manager & Construction \\
\hline
\end{tabular}

Data on awareness of serious gaming for each participant shows that there is little awareness of serious gaming among the South African corporate (See Table 2). Since none of the participants had used serious gaming only one of the eight respondents (Participant D) demonstrated a proper understanding of the concept of serious gaming, while two others (Participant A and Participant G) indicated partial awareness of the concept.

Table 2. Awareness of serious gaming concepts

\begin{tabular}{|c|c|c|c|c|c|c|c|c|c|}
\hline \multirow[t]{2}{*}{ Area of awareness } & \multicolumn{8}{|c|}{ Participant } & \multirow[t]{2}{*}{$\%$} \\
\hline & A & B & $\mathrm{C}$ & $\mathrm{D}$ & $\mathrm{E}$ & $\mathrm{F}$ & $\mathrm{G}$ & $\mathrm{H}$ & \\
\hline Concept awareness & No & $\mathrm{No}$ & $\mathrm{No}$ & Yes & $\mathrm{No}$ & No & No & $\mathrm{No}$ & $13 \%$ \\
\hline Partial concept awareness & Yes & No & $\mathrm{No}$ & No & $\mathrm{No}$ & $\mathrm{No}$ & Yes & No & $25 \%$ \\
\hline Benefits awareness & Yes & No & No & Yes & No & No & Yes & No & $38 \%$ \\
\hline Partial benefits awareness & No & No & Yes & No & No & No & No & No & $13 \%$ \\
\hline Limitations awareness & Yes & Yes & No & Yes & No & Yes & Yes & No & $63 \%$ \\
\hline
\end{tabular}

Participant D became aware of serious gaming (more specifically DGBL) at a learning conference in 2010 where "there was an international speaker and he was very, very keen to bring in some kind of digital gaming for learning into Africa”. The other participants who were partially aware of serious gaming understood it in relation 
to gamification (Participant G), or generally as "a way to aid learning by using technology so that learning is more practical, hands on, [and] simulated" (Participant A). Although there is very little awareness of the concept of serious gaming, there is slightly more aware of the potential benefits that gaming can provide in a corporate context. Four of the eight participants acknowledged the benefits of serious gaming:

“...you're able to engage more as a learner...I think one of the big advantages is you can learn alone, you don't always have to rely on group learning. One of the disadvantages of group learning is that you sometimes have to go at the pace of the average learner, so your slower learners need more attention and your quicker learners actually get quite impatient. So when you're able to engage with technology, you can cater more to individuals."

- Participant A

"It could even be used in our company which is a construction company and it could be used in simulation for our [crane] operators which could be very beneficial to the company."

- Participant C

"If you continuously use gaming I think you are able to learn concepts faster without even realising that you are, you know, by the very repetitive nature of gaming, because if you like something you'll do it over and over again, you would probably be learning much more."

- Participant D

“...introducing a gaming element provides an experience that people almost learn while they play kind of thing. So I think if you're looking to drive up knowledge and skill levels, using gaming techniques can help do that in the business context other than, sort of, traditional training methods.'

- Participant G

Participants were more aware of the limitations than the benefits or the concept of serious games. Five of the eight participants $(63 \%)$ identified limitations of gaming in the corporate environment. Although more participants were more aware of the limitations than benefits of serious games, their descriptions of the limitations were less detailed and more abstract than descriptions of the benefits. Limitations include; the impracticality of using games for certain business activities: "You're not going to be able to convert every kind of organisational functioning into some sort of gaming concept...without losing something in the process" (Participant G), and target audiences: "...it probably depends on the target audience... I think it would be very suited for the new generation of trainees or staff” (Participant F). Participant B highlighted the need for a broader strategic programme to ensure serious games are used appropriately: "They should be effective within a proper context of a strategy to utilise learning technology to support development of [the] businesses".

Positive relationship exists between the participants' level of awareness and their attitude towards serious gaming. As participants' awareness of serious gaming (the concept, benefits and limitations) improve, attitude towards serious gaming became move toward positive. An exception to this rule is Participant $\mathrm{G}$ who demonstrated higher than average awareness of serious gaming and was not particularly positive about the prospects of serious gaming. Upon closer review, it became apparent that the lack of positivity shown by Participant $G$ is not directed at serious gaming in general, but specifically at using serious gaming within her particular company: 
"I think there is value [in serious games]... you've got to be careful that you don't try and take the next biggest thing and make it the only thing, especially depending on the kind of business we have... It's not an easy fit for the kind of business we are. We're an insurance business... a more traditional kind of conservative business. The profile of employee and customer we have are probably not your target market for that typically."

- Participant G

A considerably low level of serious gaming awareness (13\%) is a significant result. The observation is even lower than the result of Azadegan et al. (2012) of awareness in the UK (29\%). The low level of awareness is likely to affect the results of the subsequent section on "Barriers to Adoption of Serious Gaming" because little is known about the concept of serious gaming itself. Participants correctly identified the potential of serious gaming for education and simulations; however, none identified the potential for collaboration or demonstrations. This could indicate that the participants understand serious gaming in a narrow scope, relating only to training.

Analysis performed is on the barriers to adoption of serious gaming using the framework defined by Azadegan et al. (2012) and the results summarized in Table 3.

Table 3. Barriers to adoption

\begin{tabular}{l|l|l|l|l|l|l|l|l|r}
\hline \multirow{2}{*}{ Type of barrier } & \multicolumn{7}{|l|}{ Participant } & \multirow{2}{*}{$\%$} \\
\cline { 2 - 10 } & A & B & C & D & E & F & G & H & \\
\hline Familiarity barriers & Yes & Yes & Yes & Yes & Yes & Yes & Yes & Yes & $\mathbf{1 0 0 \%}$ \\
\hline Financial barriers & No & No & No & Yes & No & No & No & No & $\mathbf{1 3 \%}$ \\
\hline Practicality barriers & Yes & No & No & No & No & Yes & Yes & No & $\mathbf{3 8 \%}$ \\
\hline IT facilities \& support barriers & Yes & No & No & No & No & No & No & No & $\mathbf{1 3 \%}$ \\
\hline
\end{tabular}

All participants reported that their lack of familiarity with serious gaming was a barrier to its adoption. The prevalence of familiarity barriers is significant, but expected, considering the preceding findings on the low level of serious gaming awareness. Practicality barriers are the second most common reason for not adopting serious gaming, as indicated by three participants (38\%). The barriers that participants described least were financial barriers (13\%) and the lack of IT facilities and support (13\%).

Lack of familiarity is more than telling as a barrier to serious gaming adoption. To analyse the data further, barriers because of familiarity is distinguishable under five related themes. The themes are game perceptions, the lack of promotion of serious gaming, the need for proven cases, unfamiliarity with the technology, and unaware of the concept of serious gaming. Refer to Table 4 distribution of these themes across the various participants.

Half the number of participants, i.e., 50\% were unaware of the concept of serious games. These participants were unable to identify other barriers to adopting serious gaming because they were uninformed of this concept, its requirements, and limitations: "I don't know much about the field...I need to get more information before I can comment" (Participant C). The other half of the participants had some amount of awareness of the concept of serious games. This informed $50 \%$ of the sample; all mentioned the lack of promotion of serious gaming (75\%) and/or called for the need for publicizing cases of serious gaming implementations $(50 \%)$. 
Table 4. Breakdown of familiarity barriers

\begin{tabular}{|c|c|c|c|c|c|c|c|c|c|}
\hline \multirow[t]{2}{*}{ Theme } & \multicolumn{8}{|c|}{ Participant } & \multirow[t]{2}{*}{$\%$} \\
\hline & A & $\mathrm{B}$ & $\mathrm{C}$ & $\mathrm{D}$ & $\mathrm{E}$ & $\mathrm{F}$ & G & $\mathrm{H}$ & \\
\hline Unaware of concept & No & Yes & Yes & No & Yes & No & No & Yes & $50 \%$ \\
\hline Lack of promotion & Yes & No & Yes & Yes & No & No & No & No & $38 \%$ \\
\hline Need proven cases & No & No & No & Yes & No & No & Yes & No & $26 \%$ \\
\hline Unfamiliar with techNology & Yes & No & No & No & No & Yes & Yes & No & $38 \%$ \\
\hline Negative perception of games & Yes & No & No & No & No & No & No & No & $13 \%$ \\
\hline
\end{tabular}

Calls for promotion of serious games in corporate and demand for public cases that had a serious games implementation. Participant $G$, who was not positive towards serious gaming, hinted at the power of successful case studies:

"...if we could get some practical, tangible case studies and examples of businesses like ours who are utilising it in certain spheres, [we] might find that there's more opportunity than we think. I might change my mind".

- Participant G

Three participants mentioned issues relating to a lack of familiarity with the technology involving serious gaming. However, the accuracy of these issues is questionable as the statements were speculative and vague: “...there's also stuff around tech-savviness, you know..." (Participant G), "I'll leave that up to our IT departments who actually do that..." (Participant F), Participant A was the only participant to suggest that negative perceptions of games, that games are easy and do not add value, among the decision makers would affect the company's adoption of serious gaming.

Only one participant $(13 \%)$ described financial barriers for adopting serious gaming:

“...to set up something like that is always costly to start with and then you realise the benefits of the learning but they don't give it quite the chance because most of us operate on the low cost operating model, so initial setup is always difficult."

- Participant D

The use of serious gaming was considered impractical firstly because of the nature of the business itself: "Our environment...doesn't lend itself well to gaming" (Participant A); and "It's not an easy fit for the kind of business we are" (Participant G). Secondly, serious gaming is impractical for the type of people the company employs: "The profile of employee and customer we have are probably not your target market for that typically" (Participant G). Thirdly, the absence of the skills needed to implement serious gaming, is why it may consider it as impractical. As explained here "I think it can be done I just don't know how it can be done" (Participant F); and "I think it's a very specialist set of expertise that know how to really utilize the serious gaming or the gamification concepts in the right way. We probably don't have that here" (Participant G).

Participant A was the only one (13\%) to mention the lack of IT facilities and support as a barrier to adoption of serious gaming. This observation conflicts with the finding of Azadegan et al. (2012) who identified that $45 \%$ of companies in the United Kingdom experienced barriers related to their IT facilities and support. Given the low 
level of serious gaming awareness, this inconsistency is likely to be the result of insufficient awareness regarding the IT requirements of serious gaming (as with the case of financial barriers).

Data obtained suggests that there is interest in serious gaming, but possibly not enough interest for companies to embark on serious games. The call for greater promotion of serious gaming and successful case studies reflects an appeal for either a driver of serious gaming - another corporate or a vendor of serious games.

Only one participant $(13 \%)$ mentioned that the perception of games might have a negative impact on their company. This observation is lower than Azadegan (18\%), which is a positive indication for the future of serious gaming in South Africa.

Practicality barriers identified relate to the lack of skills for serious gaming, or the limitations of serious games. Scarcity of serious gaming skills is due to widespread lack of awareness and the adoption. The more companies adopt serious gaming, the more people would acquire the skills necessary to teach and learn the use of serious games. Considering the low level of serious gaming awareness, companies may already possess the skills for using serious gaming that is yet unrecognized by them.

The inability of most participants to identify barriers in terms of finance and IT facilities and support is a further indication of low awareness of serious gaming. South Africa presents numerous relevant IT challenges, such as the high cost of internet bandwidth (Gillwald 2009). Azadegan et al. (2012) found that $45 \%$ of companies identified IT facilities and support barriers, compared with $13 \%$ in this study. This to mean that participants' inability to identify these barriers indicates a low level of readiness to adopt serious gaming in South Africa.

Analysis carried out on the use of technologies related to serious gaming for each participant. This examination assists in knowing the extent of each participant's technology profile and inclination to use technologies like serious gaming. The technologies of interest are electronic learning, collaborative tools, and simulation tools. For the result of that summarize the analysis, refer to Table 5.

Table 5. The use of related technologies

\begin{tabular}{|c|c|c|c|c|c|c|c|c|c|}
\hline \multirow[t]{2}{*}{ Technology } & \multicolumn{8}{|c|}{ Participant } & \multirow[t]{2}{*}{$\%$} \\
\hline & A & $\mathrm{B}$ & $\mathrm{C}$ & $\mathrm{D}$ & $\mathrm{E}$ & $\mathrm{F}$ & $\mathrm{G}$ & $\mathrm{H}$ & \\
\hline E-Learning & Yes & Yes & No & Yes & Yes & Yes & No & No & $63 \%$ \\
\hline Collaborative tools & Yes & Yes & Yes & Yes & Yes & Yes & Yes & No & $88 \%$ \\
\hline Digital simulations & Yes & Yes & Yes & Yes & Yes & Yes & Yes & No & $88 \%$ \\
\hline Physical simulations & No & No & No & No & Yes & Yes & Yes & No & $38 \%$ \\
\hline
\end{tabular}

Seven participants $(88 \%)$ reported that they currently use two or more of the related technologies in their corporations. Five participants $(63 \%)$ currently use all three technologies (E-learning, collaborative tools and digital simulations). Participant $\mathrm{H}$ is the only participant that does not use any related technologies.

Digital simulations were used by $88 \%$ of participants, and $38 \%$ also used physical simulations. The purpose of the simulations was to teach system usage or to simulate a 
business process as part of training. The extensive use of related technologies by the participants demonstrates their awareness of the technologies and they had the capabilities for implementing them. This implies the participants have the willingness, budget, and skills to implement technologies like serious gaming. The participants with the least use of related technologies are Participant $\mathrm{C}$ and Participant $\mathrm{H}$, both of which are in the construction industry. This result may be an indication that the construction industry in general is averse to the related technologies, or that the technologies are impractical in the construction industry. The former is more likely to be true considering the potential of serious gaming for improving construction site safety (Connolly et al. 2012) and visualizing landscapes and architecture (Herrlich 2007).

On the potential for Serious Gaming in South Africa and based on the feedback from participants, there appear to be various opportunities for the use of serious gaming in South Africa. A benefit of serious gaming that is relevant to the participants is its ability to assemble groups of geographically dispersed people. These virtual gatherings are beneficial for corporations because they enable collaboration and training on a large scale without the associated travel and lodging expenses. Data suggests that serious gaming may be useful for dealing with geographically dispersed employees. This observation supports the finding of Ives and Junglas (2008) who identified the benefits by using serious games to connect dispersed people in a virtual world. The data indicates a demand for technology that will improve access to knowledge and reduce operating costs. Connolly et al. (2012) found that serious gaming improves knowledge acquisition, which suggests that the participants will be more inclined to adopt serious gaming if it is not more expensive than their current training methods.

\section{Conclusion}

The researchers show that none of the participating corporations had used serious gaming and only one participant (13\%) was aware of the concept. Familiarity barriers were the most common reason for not adopting serious gaming (100\%), highlighting the scarcity of serious gaming knowledge. A key finding was the demand for greater promotion of serious gaming and publicised cases of serious gaming implementations. The majority of participating corporations were interested in serious gaming, although previously unaware of it, and sought more information on the topic. This could represent an opportunity for a serious gaming vendor to enter the South African market and drive the adoption of serious gaming. Another key finding to emerge from the data was the widespread use of e-learning, collaborative tools, and simulation tools. By providing an outline of the current state of South African corporations, this study forms the foundation for future research into the adoption and usage of serious games. This research may be of particular interest to South African corporate considering the use of serious gaming, as well as serious games vendors. 


\section{References}

Azadegan, A., Riedel, J.C.K.H., Baalsrud Hauge, J.: Serious games adoption in corporate training. In: Ma, M., Oliveira, M.F., Hauge, J.B., Duin, H., Thoben, K.-D. (eds.) SGDA 2012. LNCS, vol. 7528, pp. 74-85. Springer, Heidelberg (2012). https://doi.org/10.1007/978-3-64233687-4_6

Azadegan, A., Riedel, J.C.K.H.: Serious games integration in companies: a research and application framework. In: IEEE 12th International Conference on Advanced Learning Technologies, pp. 485-487 (2012)

Bergeron, B.: Developing Serious Games. Thompson Delmar Learning, Hingham (2006)

Bozanta, A., Kutlu, B., Nowlan, N., Shirmohammadi, S.: Multi user virtual environments and serious games for team building. Procedia Comput. Sci. 15, 301-302 (2012)

Breuer, J., Bente, G.: Why so serious? On the relation of serious games and learning. Eludamos J. Comput. Game Cult. 4(1), 7-24 (2010)

Cohen, D.: OXO aka Noughts and Crosses - The First Video Game. About.com: Classic Video Games (2009)

Connolly, T.M., Boyle, E.A., MacArthur, E., Hainey, T., Boyle, J.M.: A systematic literature review of empirical evidence on computer games and serious games. Comput. Educ. 59(2), 661-686 (2012)

Cox, T.: Online and multiplayer gaming - an overview. Virtual Reality 5(4), 215-222 (2000)

Csikszentmihalyi, M.: Flow: The Psychology of Optimal Performance. Harper and Row, New York (1990)

Est, C., Poelman, R., Bidarra, R.: High-level scenario editing for serious games. In: Proceedings of GRAPP, pp. 339-346. Delft University of Technology, Delft (2011)

Fernandes, J., Duarte, D., Ribeiro, C., Farinha, C., Pereira, J.M., Silva, M.M.: iThink: a gamebased approach towards improving collaboration and participation in requirement elicitation. Procedia Comput. Sci. 15, 66-77 (2012)

Gillwald, A.: Between two stools: broadband policy in South Africa. Southern African J. Inf. Commun. 8, 53-77 (2009)

Graafland, M., Schraagen, J.M., Schijven, M.P.: Systematic review of serious games for medical education and surgical skills training. Br. J. Surg. 99(10), 1322-1330 (2012)

Grossman, L.: The Army's Killer App. Time 165, 43-44 (2005)

Halter, E.: From Sun Tzu to Xbox: War and Video Games, pp. 1-364. Thunder Mouth Press, New York (2006)

Harrison Jr., J.: Computer-Aided Information Systems for Gaming. Mclean VA (1964)

Herrlich, M.: A tool for landscape architecture based on computer game technology. In: 17th International Conference on Artificial Reality and Telexistence (ICAT) 2007, pp. 264-268 (2007)

Ives, B., Junglas, I.: APC forum: business implications of virtual worlds and serious gaming. MIS Q. Exec. 7(3), 151-156 (2008)

Jones, C., Ramanau, R., Cross, S., Healing, G.: Net generation or digital natives: is there a distinct new generation entering university? Comput. Educ. 54(3), 722-732 (2010)

Levin, M.: 3D internet and enterprise: emergence of virtual worlds and serious games in the workplace. Dev. Learn. Organ. 24(2), 17-20 (2010)

Loguidice, B., Matt, B.: Vintage Games: An Insider Look at the History of Grand Theft Auto, Super Mario, and the Most Influential Games of All Time, pp. 1-408. Focal Press, Waltham (2009) 
MacBeth, T.M.: Psychology of media use. In: Downing, J.D.H., McQuail, D., Schlesinger, P., Wartella, E. (eds.) The SAGE Handbook of Media Studies, pp. 201-225. SAGE Publications Inc., New York (2004)

Michael, D.R., Chen, S.: Serious Games: Games that Educate, Train and Inform, 1st edn. Thomson Course Technology, Boston (2006)

Montfort, N.: Twisty Little Passages: An Approach to Interactive Fiction. The MIT Press, Cambridge (2005)

Moodley, K.: African Renaissance and language policies in comparative perspective. Politikon 27(1), 103-115 (2000)

Myers, M.D.: Qualitative Research in Business \& Management, pp. 1-275. SAGE Publications Inc, London (2009)

Oliveira, V., Coelho, A., Guimarães, R., Rebelo, C.: Serious games in security: a solution for security trainees. Procedia Comput. Sci. 15, 274-282 (2012)

Piccione, P.A.: In search of the meaning of senet. Archaeology 33, 55-58 (1980)

Rankin, Y.A., Shute, M.W.: Re-purposing a recreational video game as a serious games for second language acquisition. In: Serious Games Design and Development: Technologies for Training and Learning, pp. 178-180. IGI Global, Hershey (2010)

Saunders, M., Lewis, P., Thornhill, A.: Research Methods for Business Students, 6th edn. Pearson, Harlow (2012)

Serious games Institute: Serious games Institute (SGI) - GaLA Network of excellence in Serious games (2011)

Smith, R.: Game impact theory: the five forces that are driving the adoption of game technologies within multiple established industries. In: The Interservice/Industry Training, Simulation \& Education Conference (I/ITSEC), pp. 1-32. National Training Systems Association (2007)

Smith, R.: A History of serious games. In: The Interservice/Industry Training, Simulation \& Education Conference (I/ITSEC), pp. 1-81. U.S Army, Orlando (2009)

Spain, J.W., Vega, G.: Sony online entertainment: EverQuest or EverCrack? J. Bus. Ethics 58(1), 3-6 (2005)

Susi, T., Johannesson, M., Backlund, P.: Serious Games - An Overview, Skövde, pp. 1-21 (2007)

Zyda, M.: From visual simulation to virtual reality to games. IEEE Comput. 38(9), 25-32 (2005) 